\title{
Kinetic Role of Carbon in Solid-State Synthesis of Zirconium Diboride using Nanolaminates: Nanocalorimetry Experiments and First-Principles Calculations
}

\section{Citation}

Lee, Dongwoo, Gi-dong Sim, Kejie Zhao, and Joost J. Vlassak. 2015. “Kinetic Role of Carbon in Solid-State Synthesis of Zirconium Diboride Using Nanolaminates: Nanocalorimetry Experiments and First-Principles Calculations." Nano Lett. (November 5). doi:10.1021/ acs.nanolett.5b03829.

\section{Published Version}

doi:10.1021/acs.nanolett.5b03829

\section{Permanent link}

http://nrs.harvard.edu/urn-3:HUL.InstRepos:23853829

\section{Terms of Use}

This article was downloaded from Harvard University's DASH repository, and is made available under the terms and conditions applicable to Open Access Policy Articles, as set forth at http:// nrs.harvard.edu/urn-3:HUL.InstRepos:dash.current.terms-of-use\#OAP

\section{Share Your Story}

The Harvard community has made this article openly available.

Please share how this access benefits you. Submit a story. 


\title{
Kinetic Role of Carbon in Solid-State Synthesis of Zirconium Diboride using Nano-Laminates: Nanocalorimetry Experiments and First-Principles Calculations
}

\author{
Dongwoo Lee ${ }^{\dagger}$, Gi-dong $\mathrm{Sim}^{\dagger}$, Kejie Zhao ${ }^{\ddagger}$, Joost J. Vlassak ${ }^{\dagger}{ }^{+*}$ \\ ${ }^{\dagger}$ School of Engineering and Applied Sciences, Harvard University, Cambridge, Massachusetts 02138, United States \\ ${ }^{\ddagger}$ School of Mechanical Engineering, Purdue University, West Lafayette, Indiana 47906, United States
}

Reactive nano-laminates afford a promising route for the low-temperature synthesis of zirconium diboride, an ultrahigh-temperature ceramic with metallic properties. Although the addition of carbon is known to facilitate sintering of $\mathrm{ZrB}_{2}$, its effect on the kinetics of the formation reaction has not been elucidated. We have employed a combined approach of nanocalorimetry and first-principles theoretical studies to investigate the kinetic role of carbon in the synthesis of $\mathrm{ZrB}_{2}$ using $\mathrm{B}_{4} \mathrm{C} / \mathrm{Zr}$ reactive nano-laminates. Structural characterization of the laminates by XRD and TEM reveal that the reaction proceeds via inter-diffusion of the $\mathrm{B}_{4} \mathrm{C}$ and $\mathrm{Zr}$ layers, which produces an amorphous $\mathrm{Zr}_{3} \mathrm{~B}_{4} \mathrm{C}$ alloy. This amorphous alloy then crystallizes to form a super-saturated $\mathrm{ZrB}_{2}(\mathrm{C})$ compound. A kinetic analysis shows that carbon lowers the energy barriers for both inter-diffusion and crystallization by more than $20 \%$. Energetic calculations based on first-principles modeling suggest that the reduction of the diffusion barrier may be attributed to the stronger bonding between $\mathrm{Zr}$ and $\mathrm{C}$ as compared to the bonding between Zr and B.

Keywords: zirconium diboride, carbon, reactive nano-laminate, nanocalorimetry, first-principles calculation

*Address correspondence to vlassak@seas.harvard.edu 
Zirconium diboride $\left(\mathrm{ZrB}_{2}\right)$, a high-performance ceramic with metallic properties, exhibits a unique combination of physical, chemical, and structural properties, making it a material of interest for a broad range of applications. Examples include its use as a substrate for group III nitride semiconductors in optoelectronic devices ${ }^{1-5}$, as support material for low-temperature fuel cells $^{6,7}$, and as a hydrogen storage medium ${ }^{8}$. Difficulties associated with synthesis, however, have hindered broad adoption of the material - production of high-density $\mathrm{ZrB}_{2}$ typically requires both extremely high temperature and pressure $^{9}$ because of its high melting point and stability. Viable synthesis methods of $\mathrm{ZrB}_{2}$ have been a topic of intense investigation for decades $5,9,10$. Additives such as carbon have been shown to improve the processability of $\mathrm{ZrB}_{2}$. It has been reported that carbon promotes removal of surface oxides in $\mathrm{ZrB}_{2}$ powders and limits grain growth, thus enhancing its sinterability ${ }^{11-14}$. The beneficial role of carbon in the formation of $\mathrm{ZrB}_{2}$-based compounds, however, is not fully understood and few studies have been conducted at the nano- to atomistic scales ${ }^{13}$.

Recent experiments ${ }^{15}$ have demonstrated low-temperature synthesis of highly textured crystalline $\mathrm{ZrB}_{2}$ coatings through use of reactive nano-laminates (RNLs) that consist of alternating layers of $\mathrm{Zr}$ and $\mathrm{B}$. The synthesis is facilitated by the formation of an intermediate amorphous phase that allows fast transport of $\mathrm{B}^{15,16}$. The notion that the addition of carbon may further facilitate synthesis of $\mathrm{ZrB}_{2}$ motivated us to investigate the phase evolution in reactive nano-laminates that contain $\mathrm{Zr}, \mathrm{B}$, and $\mathrm{C}$. In this report, we combine nanocalorimetry and abinitio simulations to study the energetics and kinetics of phase evolution in $\mathrm{Zr} / \mathrm{B}_{4} \mathrm{C}$ RNLs.

We demonstrate that, as temperature increases, the crystalline $\mathrm{Zr}$ and amorphous $\mathrm{B}_{4} \mathrm{C}$ layers of the RNLs intermix to form an amorphous compound. In a subsequent step, this amorphous compound crystallizes to form a textured $\mathrm{ZrB}_{2}$ coating that is supersaturated with 
carbon. A kinetics analysis of the nanocalorimetry results reveals that the activation energies of both diffusion and crystallization are reduced by more than $20 \%$ compared to the reaction in RNLs without carbon. Ab-initio calculations on $\alpha-\mathrm{Zr}$ with a $\mathrm{C}$ atom at various interstitial sites reveal that $\mathrm{Zr}$ and $\mathrm{C}$ bond more strongly than $\mathrm{Zr}$ and $\mathrm{B}$, thus facilitating inter-diffusion of $\mathrm{B}$. The finding suggests that $\mathrm{C}$ doping may be an effective strategy to facilitate $\mathrm{ZrB}_{2}$ synthesis.

The micromachined nanocalorimetry sensors used in this study have been described in detail elsewhere in the literature ${ }^{17-19}$; a brief description of the sensors and experimental details are provided in the methods section. RNLs consisting of alternating $\mathrm{Zr}$ and $\mathrm{B}_{4} \mathrm{C}$ layers were sputter deposited directly onto the nanocalorimetry sensors as illustrated schematically in the inset of Figure 1a. The thickness of each layer was determined to ensure a stoichiometric composition: as-deposited samples had a 3:1 molar ratio of $\mathrm{Zr}: \mathrm{B}_{4} \mathrm{C}$, to produce a 2:1 molar ratio of $\mathrm{ZrB}_{2}: \mathrm{ZrC}$ after reaction. Figure 1 shows, as a function of temperature, the heat flow produced by $\mathrm{Zr} / \mathrm{B}_{4} \mathrm{C}$ nano-laminates with bilayer periods of (a) $5 \mathrm{~nm}$ and (b) $10 \mathrm{~nm}$. In order to characterize the kinetics of the reaction, scanning rates were varied from 4,800 K/s to $56,600 \mathrm{~K} / \mathrm{s}$ as indicated in the figures. 
(a)

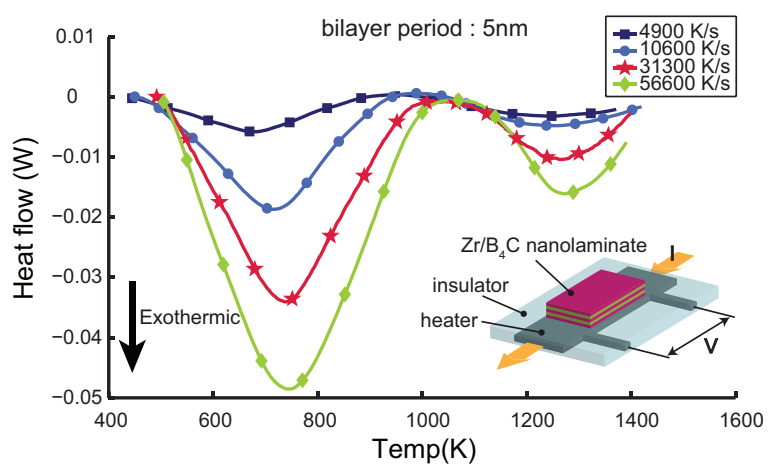

(b)

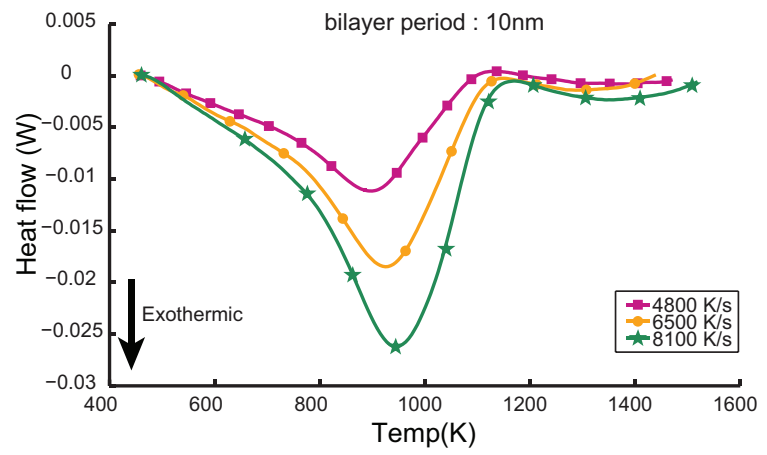

(c)

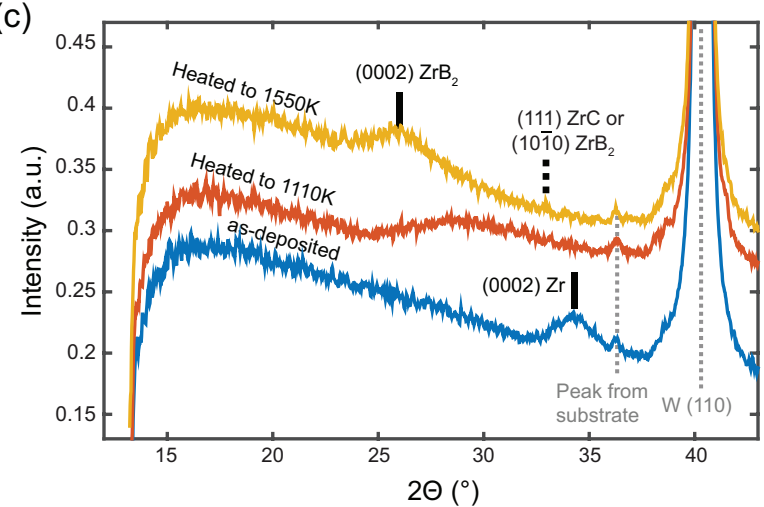

(d)

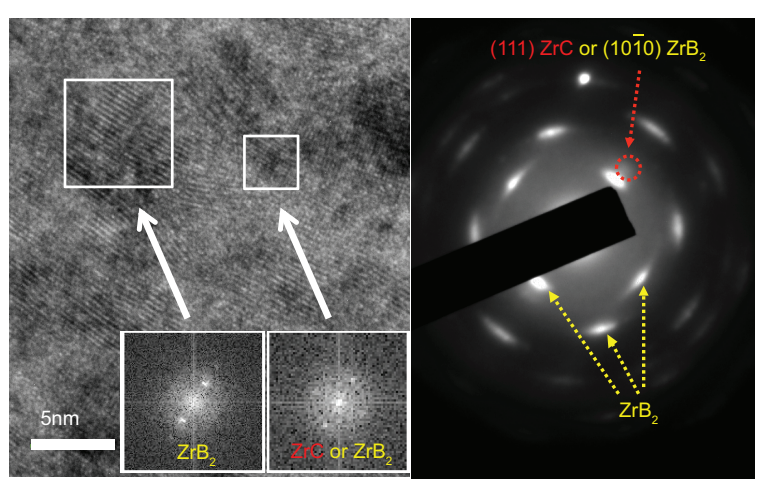

FIGURE 1. Heat flow vs. temperature for $\mathrm{Zr} / \mathrm{B}_{4} \mathrm{C}$ nano-laminates with bilayer periods of (a) $5 \mathrm{~nm}$ and (b) $10 \mathrm{~nm}$ measured using nanocalorimetry. Nanocalorimetry heating rates are indicated in the insets of the figures (c) XRD results for an as-deposited nano-laminate (bilayer period: $10 \mathrm{~nm}$ ), and for nano-laminates heated to 1110 and $1550 \mathrm{~K}$ (scanning rate: $8100 \mathrm{~K} / \mathrm{s}$ ). (d) Cross-sectional TEM micrographs for a nano-laminate heated to $1550 \mathrm{~K}$ : (left) bright-field image with Fourier transform analyses for selected regions and (right) diffraction pattern.

The heat flow curves in Figure 1a, b clearly show that the reaction in the $\mathrm{Zr} / \mathrm{B}_{4} \mathrm{C}$ RNLs proceeds in two distinct stages, each represented by an exothermic peak. The stage that corresponds to the first exotherm starts around 400-500 K for all samples tested. This stage of the reaction is complete at temperatures below $1000 \mathrm{~K}$ for the samples with a $5 \mathrm{~nm}$ bilayer period, and below $1150 \mathrm{~K}$ for the samples with a $10 \mathrm{~nm}$ period. Faster heating rates and larger bilayer periods result in higher peak temperatures. The second stage is completed at 
approximately $1400 \mathrm{~K}$ for the samples with a $5 \mathrm{~nm}$ bilayer period, and at $1550 \mathrm{~K}$ for the $10 \mathrm{~nm}$ samples. Again, faster heating rates and larger bilayer periods shift the peak temperatures to higher values, but the effect is less pronounced than for the first stage.

To determine the phase evolution of the RNLs during the two stages of the reaction, Xray diffraction (XRD) was performed on RNLs with a $10 \mathrm{~nm}$ bilayer period in the as-deposited state, heated to an intermediate temperature $(1110 \mathrm{~K})$ and quenched, and after completion of the second exothermic reaction $(1550 \mathrm{~K})$. As shown in Figure 1c, the as-deposited sample has a diffraction peak corresponding to crystalline $\mathrm{Zr}$ with a (0002) fiber texture (Powder Diffraction File \#050665). No other reflections are identified, indicating that the as-deposited RNL consists of crystalline $\mathrm{Zr}$ and amorphous $\mathrm{B}_{4} \mathrm{C}$. The intermediate sample has a broad peak corresponding to an amorphous structure. This result implies that the first exothermic peak in the calorimetric signal is caused by the intermixing and amorphization of the $\mathrm{Zr}$ and $\mathrm{B}_{4} \mathrm{C}$ layers in the laminate, explaining the shift to higher temperatures of the first calorimetry peak as the bilayer period, and thus the diffusion distance, increases. The sample heated to $1550 \mathrm{~K}$ has a strong diffraction peak corresponding to the (0002) $\mathrm{ZrB}_{2}$ reflection (Powder Diffraction File \#340423), and a very small peak caused by the (10-10) $\mathrm{ZrB}_{2}$ or the (111) $\mathrm{ZrC}$ (Powder Diffraction File \#350784) reflections - evidently, the second stage in the reaction corresponds to the crystallization of the amorphous phase to form a supersaturated, crystalline $\mathrm{ZrB}_{2}$ phase, with possibly a small amount of $\mathrm{ZrC}$. The $\mathrm{XRD}$ results suggest that the crystallographic texture of the $\mathrm{ZrB}_{2}$ films is composed primarily of a (0002) fiber texture. Transmission electron microcopy (TEM) performed on the same sample confirms the XRD findings as shown in Figure 1d. This texture, together with the small crystallite size, suggests that the crystalline phase nucleates preferentially at the original interfaces of the $\mathrm{RNLs}^{15}$ or that remanent concentration gradients at these interfaces induce a 
preferred nucleus orientation. These arguments are further supported by the observation that the peak crystallization temperature decreases with decreasing bilayer period, i.e., with increasing density of original interfaces.

The total reaction enthalpy is calculated by integrating the heat flow curves in Figures 1a and $1 \mathrm{~b}$ with respect to time. The reaction enthalpy is independent of the heating rate, but varies with the bilayer period of the RNLs because of a small amount of intermixing that occurs during sputter-deposition of the nano-laminates: samples with a $5 \mathrm{~nm}$ period released $392 \pm 72 \mu \mathrm{J}$, while $10 \mathrm{~nm}$ period samples produced $784 \pm 117 \mu \mathrm{J}$, respectively $19.7 \pm 3.6$ and $39.5 \pm 5.9 \%$ of the theoretical enthalpy for the reaction of $3 \mathrm{Zr}+\mathrm{B}_{4} \mathrm{C} \rightarrow 2 \mathrm{ZrB}_{2}+\mathrm{ZrC}^{20}$. The enthalpies associated with the first stage of the reaction are $295 \pm 55$ and $727 \pm 93 \mu \mathrm{J}$, respectively. Given that the total thickness of the two sets of laminates is the same and that the total volume of initially intermixed material is two times larger for the samples with the $5 \mathrm{~nm}$ period than for the samples with the 10 $\mathrm{nm}$ period, the thickness of the intermixed layer can be estimated as approximately $1.9 \mathrm{~nm}$ per interface. This estimate is based on the assumption that the intermixed layers are fully intermixed, i.e., they release no enthalpy on heating other than during the crystallization process. After correcting for the presence of the intermixed layers, the enthalpy of formation of the amorphous phase is found to be $1160 \pm 190 \mu \mathrm{J}$, approximately $60 \%$ of the enthalpy of formation of pure crystalline $\mathrm{ZrB}_{2}$ and $\mathrm{ZrC}$ in a 2:1 molar ratio.

The sequence of inter-diffusion and crystallization in the $\mathrm{Zr} / \mathrm{B}_{4} \mathrm{C}$ RNLs is similar to the sequence observed in RNLs that consist of alternating $\mathrm{Zr}$ and amorphous $\mathrm{B}^{15}$ layers. Thus we adopt the diffusion model developed for the $\mathrm{Zr} / \mathrm{B}$ system to characterize the first exothermic reaction in the $\mathrm{Zr} / \mathrm{B}_{4} \mathrm{C} \mathrm{RNLs}^{15}$. According to this model, there exists a simple relationship between the rate at which enthalpy is produced during the reaction and the rate of inter-diffusion: 
$\left(H+H_{o}\right) \mathrm{d} H / \mathrm{d} t$ at a given temperature is proportional to the diffusivity at that temperature. Here, $H$ is the enthalpy released during the exothermic reaction and $H_{\mathrm{o}}$ is the enthalpy that corresponds to the initially mixed $\mathrm{Zr} / \mathrm{B}_{4} \mathrm{C}$ interface layers. Figure 2 a shows graphs of $\ln ((H+$ $\left.H_{o}\right) \mathrm{d} H / \mathrm{d} t$ ) versus $1 / k_{B} T$ over the temperature range of the first exotherm for several samples. The graphs are nearly linear and have a slope of $0.37 \pm 0.08 \mathrm{eV}$, regardless of bilayer period or heating rate. This slope is the activation energy for the inter-diffusion process ${ }^{15,21,22}$.
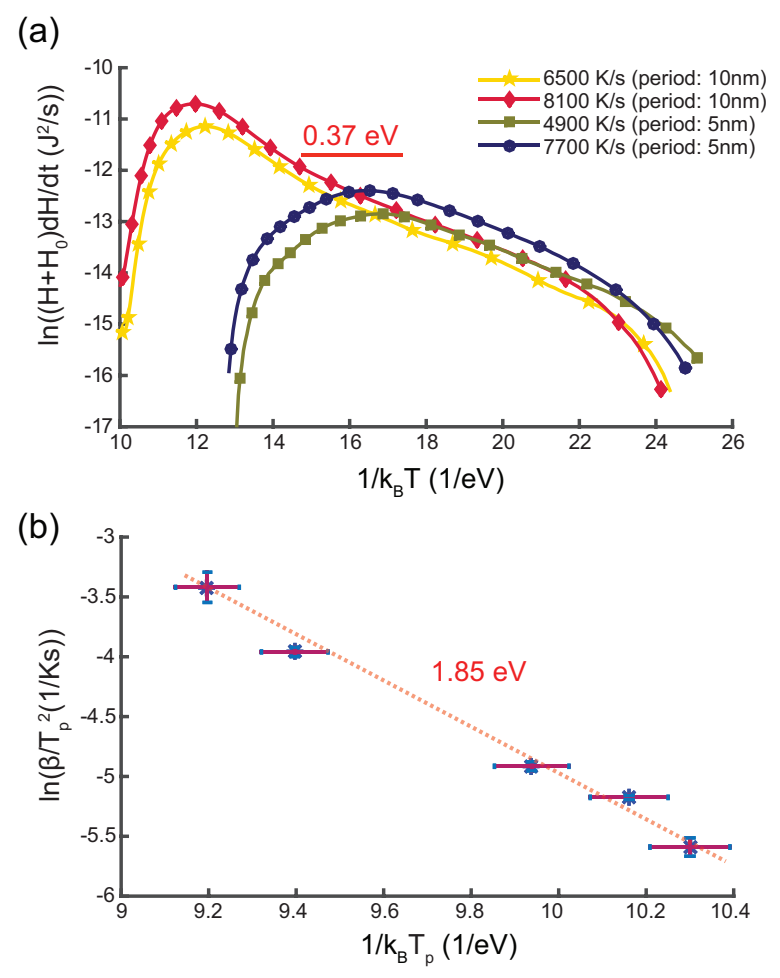

FIGURE 2. Kinetic analyses of the reactions in $\mathrm{Zr} / \mathrm{B}_{4} \mathrm{C}$ RNLs: (a) $\ln \left(\left(\boldsymbol{H}+\boldsymbol{H}_{\boldsymbol{o}}\right) \mathbf{d} \boldsymbol{H} / \mathbf{d} \boldsymbol{t}\right)$ versus $\mathbf{1} / \boldsymbol{k}_{B} \boldsymbol{T}$ over the temperature range of inter-diffusion between $\mathrm{Zr}$ and $\mathrm{B}_{4} \mathrm{C}$. (b) Kissinger analysis of the crystallization peaks of the nano-laminates with a $5 \mathrm{~nm}$ bi-layer period.

The kinetics of the crystallization step can be characterized using a Kissinger analysis ${ }^{23}$ of the crystallization peak temperature, yielding an activation energy of $1.85 \pm 0.34 \mathrm{eV}$ (Figure 
2b). This value is much larger than the activation energy for inter-diffusion, which is consistent with the observation that the crystallization peak temperature is less sensitive to the heating rate than the inter-diffusion peak (Figure 1). The activation energies for diffusion and crystallization obtained for the $\mathrm{Zr} / \mathrm{B}_{4} \mathrm{C}$ RNLs are approximately $20 \%$ smaller than the values for the $\mathrm{Zr} / \mathrm{B}$ $\mathrm{RNLs}^{15}$. Since the nano-laminates were synthesized in high vacuum without any exposure to air, our results suggest that carbon enhances the formation of $\mathrm{ZrB}_{2}$, not by the removal of surface/interfacial oxides as observed in the sintering of $\mathrm{ZrB}_{2}$ powders ${ }^{11-14}$, but by lowering the energy barriers associated with the formation reactions.

The formation of amorphous phases in both $\mathrm{Zr} / \mathrm{B}_{4} \mathrm{C}$ and $\mathrm{Zr} / \mathrm{B}^{15}$ nano-laminates upon intermixing can be explained by the large differences in the atomic sizes of the constituent atoms (atomic radius of $\mathrm{Zr}, \mathrm{B}$, and $\mathrm{C}$ are $1.62 \AA, 0.90 \AA$, and $0.77 \AA$, respectively ${ }^{24}$ ), the low solubility of $\mathrm{B}$ and $\mathrm{C}$ in $\mathrm{Zr}$, and the steep concentration gradients at the interfaces of the RNLs, which suppress nucleation of the crystalline phase $\mathrm{e}^{25-29}$. However, the lower activation energies for interdiffusion and crystallization in the $\mathrm{Zr} / \mathrm{B}_{4} \mathrm{C}$ system compared to the $\mathrm{Zr} / \mathrm{B}$ system are somewhat surprising because the addition of more elements to a compound typically enhances its glass forming ability and lowers the diffusivity of its constituent atoms ${ }^{26,30-32}$.

In order to gain a better understanding of the mechanism responsible for lowering the activation energies for inter-diffusion and crystallization, we have performed first-principles calculations on $\alpha-\mathrm{Zr}\left(\mathrm{P}_{3} / \mathrm{mmc}, a=b=3.23 \AA\right.$, and $\left.c=5.17 \AA^{33,34}\right)$ containing $\mathrm{C}$ atoms at various interstitial sites. We only consider stable or metastable sites where the $\mathrm{C}$ atom is stabilized at the initial interstitial position upon energetic relaxation ${ }^{16}$. These sites include the octahedral site (Oct), the crowdion site $(\mathrm{Cd})$, the basal bond center site $(\mathrm{Bc})$, the hexagonal site (Hex), and the plane center (Pc) site. Positions and local environments of the sites are depicted in 
Figure 3. We also consider the substitutional site (Sub) as a reference. To determine the thermodynamic stability, the formation energy per $\mathrm{C}$ atom can be calculated for each interstitial site using the following expression,

$$
E_{f \mathrm{C}}(n)=\left[E_{n \mathrm{C}-\mathrm{Zr}}-(54-m) E_{\mathrm{Zr}}-n E_{\mathrm{C}}\right] / n .
$$

We take the energies of a $\mathrm{Zr}$ atom $\left(E_{\mathrm{Zr}}\right)$ and a $\mathrm{C}$ atom $\left(E_{\mathrm{C}}\right)$ in bulk form as reference energies, with $E_{n \mathrm{C}-\mathrm{Zr}}$ the total energy of a system containing $n \mathrm{C}$ atoms in a super-cell that contains $(54-m)$ $\mathrm{Zr}$ atoms $(m=0$, except when $\mathrm{C}$ is at the Sub site, in which case $m=1)$.

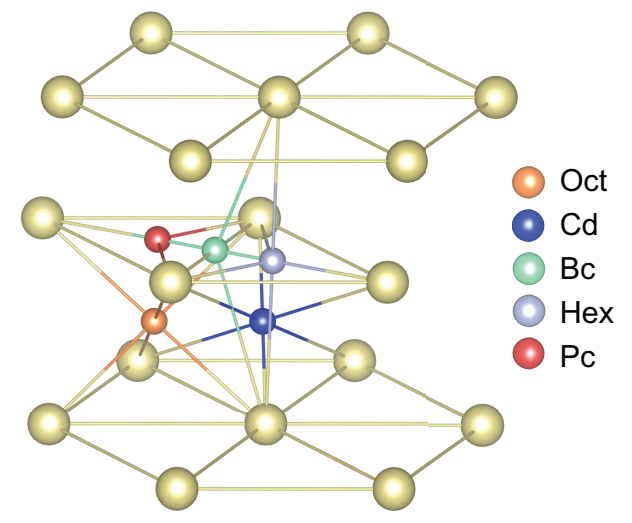

FIGURE 3. Positions and local environments of the interstitial sites in $\mathrm{Zr}$

TABLE 1. Structural and energetic features of a single $\mathrm{C}$ or $\mathrm{B}$ atom at various sites in the $\mathrm{Zr}$ lattice

$\begin{array}{ccccc}\text { Interstitial sites } & \text { Position } & \mathrm{CN} & E_{f \mathrm{C}}(\mathrm{eV}) & E_{f \mathrm{~B}}(\mathrm{eV})^{16} \\ \text { Octahedral (Oct) } & (0.33,0.67,0.25) & 6 & -1.53 & -0.53 \\ \text { Crowdion (Cd) } & (0.83,0.17,0.25) & 6 & 0.029(1.56) & 0.59(1.12) \\ \text { Basal bond center } & (0.67,0.83,0.50) & 6 & -0.046(1.48) & 0.82(1.35) \\ \text { (Bc) } & & & 0.303(1.83) & 1.45(1.98) \\ \text { Hexahedral (Hex) } & (0.00,0.00,0.50) & 5 & 2.16(3.69) & 2.18(2.71) \\ \text { Plane Center (Pc) } & (0.33,0.67,0.50) & 3 & 3.98 & 1.86 \\ \text { Substitutional (Sub) } & (0,0,0) & 12 & & \end{array}$


Table 1 lists calculated values for $E_{f C}$ at various sites. $\mathrm{CN}$ represents the coordination number, which is calculated using a cut-off length of $110 \%$ of the $\mathrm{Zr}-\mathrm{C}$ bond length in crystalline $\operatorname{ZrC}(2.36 \AA)$. We also list the formation energy per B atom $\left(E_{f \mathrm{~B}}\right)$ at each interstitial site in $\mathrm{Zr}$ for comparison ${ }^{16}$. The most stable site for $\mathrm{C}$ in $\mathrm{Zr}$ is the Oct site, which is also the most stable site for B in Zr. The Sub site is energetically very costly for both C and B atoms, indicating that both $\mathrm{B}$ and $\mathrm{C}$ are transported in the $\mathrm{Zr}$ lattice via an interstitial rather than a substitutional mechanism.

The values in parentheses in the last two columns of Table I represent the static energy barrier $\left(\Delta E_{s}\right)$, a measure of the energy barrier for a given diffusion path ${ }^{16,35} . \Delta E_{s}$ can be estimated by subtracting $E_{f \mathrm{C}}$ or $E_{f \mathrm{~B}}$ for each interstitial site from that of the most stable site (Oct). Interestingly, the Oct-Bc-Oct transition yields the lowest value for $\mathrm{C}\left(\Delta E_{s}=1.48 \mathrm{eV}\right)$, while $\mathrm{B}$ has a preferred diffusion path of Oct-Cd-Oct $\left(\Delta E_{s}=1.12 \mathrm{eV}\right)$. These results suggest that $\mathrm{C}$ diffuses faster along the c-axis, while B diffuses preferentially within the basal plane. Note that the barrier for diffusion in $\mathrm{Zr}$ is larger for $\mathrm{C}$ than for $\mathrm{B}$, for most of the cases considered. Thus, the enhanced inter-diffusion between $\mathrm{Zr}$ and $\mathrm{B}$ in the presence of $\mathrm{C}$ is not caused by the intrinsic diffusion properties of $\mathrm{C}$ in $\mathrm{Zr}$. Instead, we submit that it arises because the interaction between $\mathrm{Zr}$ and $\mathrm{C}$ is stronger than between $\mathrm{Zr}$ and $\mathrm{B}$ - indeed, as shown in Table I, C has a lower energy in all interstitial sites of $\mathrm{Zr}$ than $\mathrm{B}$. The stronger bonding between $\mathrm{Zr}$ and $\mathrm{C}$ enhances the amorphization of the $\mathrm{Zr}$ lattice in the course of intermixing and thus facilitates the transport of $\mathrm{B}$ through the resulting amorphous phase. The presence of $\mathrm{C}$ decreases the equilibrium concentration of $\mathrm{B}$ at the amorphous $\mathrm{ZrB}_{\mathrm{x}} \mathrm{C}_{\mathrm{y}} / \alpha-\mathrm{Zr}$ phase boundary compared to $\mathrm{Zr} / \mathrm{B}$ RNLs. 
Previous ab-initio simulations ${ }^{16}$ have shown that the diffusion activation energy decreases with decreasing $\mathrm{B}$ concentration in $\mathrm{ZrB}_{\mathrm{x}}, 0<\mathrm{X} \leq 1$, in line with our observation here.

Carbon also reduces the activation energy for crystallization. We believe that this is not the result of enhanced mobility of the constituent atoms - on the contrary, we would expect the presence of $\mathrm{C}$ in a homogenous amorphous $\mathrm{ZrB}_{2}$ alloy to reduce the mobility of all atoms ${ }^{26,30,31}$. Our experimental results show that the enthalpy of crystallization is larger for $\mathrm{Zr} / \mathrm{B}_{4} \mathrm{C}$ than for $\mathrm{Zr} / \mathrm{B} \mathrm{RNLs}^{15}$. This observation suggests that the reduced activation energy for crystallization may be caused by a larger free energy difference between the amorphous phase and the crystalline product. According to classical nucleation theory ${ }^{36}$, a larger free energy difference increases the thermodynamic driving force for crystallization and lowers the nucleation barrier, resulting in a reduced activation energy for the crystallization process.

In conclusion, we have studied the thermodynamics and kinetics of the inter-diffusion and crystallization of $\mathrm{Zr} / \mathrm{B}_{4} \mathrm{C}$ RNLs by combining nanocalorimetry and first-principles calculations. Nanocalorimetry and structural characterization reveal intermixing of the two constituent layers of the RNLs upon heating, followed by crystallization to form a $\mathrm{ZrB}_{2}$ phase that is super-saturated with C. A diffusion model for a multilayered system with crystalline and amorphous phase boundaries and a Kissinger analysis reveal that the $\mathrm{Zr} / \mathrm{B}_{4} \mathrm{C}$ RNLs have lower energy barriers for both inter-diffusion and crystallization than $\mathrm{Zr} / \mathrm{B}$ RNLs. First-principles calculations suggest that the lower energy barrier for inter-diffusion is not caused by the diffusional properties of $\mathrm{C}$ in the $\mathrm{Zr}$ lattice, but rather by the stronger interactions between $\mathrm{Zr}$ and C. The reaction thermodynamic and kinetics discussed in this work can provide guidance for optimizing the fabrication process of $\mathrm{ZrB}_{2}$ coatings. 


\section{METHODS}

Each micromachined nanocalorimetry sensor consists of a $100 \mathrm{~nm}$ Ti-W alloy four-point electrical probe that serves both as a resistance thermometer and as a Joule heater. The element is encapsulated and is supported by a freestanding $300 \mathrm{~nm} \mathrm{Si} \mathrm{N}_{4}$ membrane. The $\mathrm{Si}_{3} \mathrm{~N}_{4}$ membrane serves to isolate sample and sensor from the ambient. Details of the operating principles and sensor fabrication procedures can be found elsewhere ${ }^{18,19}$.

$\mathrm{Zr} / \mathrm{B}_{4} \mathrm{C}$ nano-laminate samples were magnetron sputter deposited (ATC 1800, AJA Int.) on the measurement section of the nanocalorimetry sensors using 99.99\% $\mathrm{Zr}$ (DC 80W, 5nm/min) and 99.95\% $\mathrm{B}_{4} \mathrm{C}(\mathrm{RF} 150 \mathrm{~W}, 0.4 \mathrm{~nm} / \mathrm{min})$ targets (Kurt J. Lesker Company). The thickness of each layer was determined to ensure a stoichiometric composition: 3:1 molar ratio of $\mathrm{Zr}: \mathrm{B}_{4} \mathrm{C}$ in the asdeposited samples to produce a 2:1 molar ratio of $\mathrm{ZrB}_{2}: \mathrm{ZrC}$ after the reaction. Nano-laminate samples with bilayer periods of $5 \mathrm{~nm}$ and $10 \mathrm{~nm}$, and a total thickness of $80 \mathrm{~nm}$ were used in this work. The area of the sample was defined using a custom made Si-shadow mask during the sputter-deposition process.

All nano-calorimetry measurements were performed inside a high-vacuum furnace with a base pressure better than $5 \times 10^{-6}$ Torr. The samples were heated to approximately $1550 \mathrm{~K}$ at heating rates from $4800 \mathrm{~K} / \mathrm{s}$ to $56600 \mathrm{~K} / \mathrm{s}$. The power input and the temperature data were utilized to determine the reactive heat flow of the nano-laminate sample following the procedures established in our previous work ${ }^{17}$.

X-ray diffraction (XRD) measurements were performed on both the as-deposited sample and on the samples heated to 1110 and $1550 \mathrm{~K}$ (D8 Discover, Bruker). TEM images were acquired for 
the sample heated to $1550 \mathrm{~K}$ using JEOL 2100 system. The TEM sample was prepared using a typical in-situ lift-out technique (INLO) ${ }^{37}$ in an focused ion beam system (Zeiss NVision 40 Dual-Beam). The samples that were heated for XRD and TEM studies were quenched with a fast cooling rate $(\sim 15000 \mathrm{~K} / \mathrm{s})$ to freeze in the structure before performing XRD or TEM.

Density functional theory calculations were performed using the Vienna ab initio simulation package $(\text { VASP })^{38}$. The projected-augmented-waves $(\text { PAW })^{39}$ with the PerdewBurke-Ernzerhof $(\mathrm{PBE})^{40}$ exchange-correlation potentials were adopted. For $\mathrm{Zr}$, the valence states were treated using a Zr_sv $\left(4 s^{2} 4 p^{6} 5 s^{2} 4 d^{2}\right)$ pseudo-potential. The C $\left(2 s^{2} 2 p^{2}\right)$ pseudopotential was employed for carbon. The cut-off energy for plane waves was set to $400 \mathrm{eV}$, and forces were converged to within $0.02 \mathrm{eV} / \AA$. We used a 54 -atom $\mathrm{Zr}$ super-cell $(3 \times 3 \times 3)$ and one $\mathrm{C}$ atom for the simulations to identify the interstitial sites. A $6 \times 6 \times 4 k$-point mesh in the Monkhorst-Pack scheme was employed for Brillouin zone sampling.

\section{AUTHOR INFORMATION}

Corresponding Author

*E-mail: vlassak@seas.harvard.edu.

Notes

The authors declare no competing financial interest.

\section{ACKNOWLEDGEMENTS}


This work was supported by the Air Force Office of Scientific Research under Grant No. FA9550-12-1-0098 and by the National Science Foundation under Grant No. DMR-1435820. It was performed in part at the Center for Nanoscale Systems at Harvard University, which is supported by the National Science Foundation under Award No. ECS-0335765, and at the Materials Research Science and Engineering Center at Harvard University, which is supported by the National Science Foundation under Award No. DMR-14-20570. K.Z. is grateful for the start-up funding provided by Purdue University and for the Haythornthwaite Foundation Initiation Grant from the American Society of Mechanical Engineering.

\section{REFERENCES}

1. Liu, R.; Bell, A.; Ponce, F. A.; Kamiyama, S.; Amano, H.; Akasaki, I. Appl Phys Lett 2002, 81, 31823184.

2. Suda, J.; Matsunami, H. J Cryst Growth 2002, 237, 1114-1117.

3. Tolle, J.; Roucka, R.; Tsong, I. S. T.; Ritter, C.; Crozier, P. A.; Chizmeshya, A. V. G.; Kouvetakis, J. Appl Phys Lett 2003, 82, 2398-2400.

4. Yamada-Takamura, Y.; Wang, Z. T.; Fujikawa, Y.; Sakurai, T.; Xue, Q. K.; Tolle, J.; Liu, P. L.; Chizmeshya, A. V. G.; Kouvetakis, J.; Tsong, I. S. T. Phys Rev Lett 2005, 95, 266105.

5. $\quad$ Carenco, S.; Portehault, D.; Boissiere, C.; Mezailles, N.; Sanchez, C. Chem Rev 2013, 113, 79818065.

6. Wu, P.; Lv, H. F.; Peng, T.; He, D. P.; Mu, S. C. Sci Rep 2014, 4, 3968.

7. Lv, H. F.; Mu, S. C. Nanoscale 2014, 6, 5063-5074.

8. Meng, S.; Kaxiras, E.; Zhang, Z. Y. Nano Lett 2007, 7, 663-667.

9. Guo, S.-Q.J Eur Ceram Soc 2009, 29, 995-1011.

10. Fahrenholtz, W. G.; Hilmas, G. E.; Talmy, I. G.; Zaykoski, J. A. J Am Ceram Soc 2007, 90, 13471364.

11. Mishra, S. K.; Das, S. K. Mater Lett 2005, 59, 3467-3470.

12. Zhu, S.; Fahrenholtz, W. G.; Hilmas, G. E.; Zhang, S. C. J Am Ceram Soc 2007, 90, 3660-3663.

13. Zhu, S.; Fahrenholtz, W. G.; Hilmas, G. E.; Zhang, S. C. Mater Sci Eng, A 2007, 459, 167-171.

14. Goutier, F.; Trolliard, G.; Valette, S.; Maître, A.; Estournès, C. J Eur Ceram Soc 2008, 28, 671-678.

15. Lee, D.; Sim, G. D.; Xiao, K. C.; Vlassak, J. J. J Phys Chem C 2014, 118, 21192-21198.

16. Lee, D.; Vlassak, J. J.; Zhao, K. Nano Lett 2015, 15, 6553-6558.

17. Lee, D.; Sim, G. D.; Xiao, K. C.; Choi, Y. S.; Vlassak, J. J. J Appl Phys 2013, 114, 214902.

18. McCluskey, P. J.; Vlassak, J. J. J Mater Res 2010, 25, 2086-2100.

19. McCluskey, P. J.; Vlassak, J. J. Thin Solid Films 2010, 518, 7093-7106.

20. Zhang, G. J.; Ando, M.; Yang, J. F.; Ohji, T.; Kanzaki, S. J Eur Ceram Soc 2004, 24, 171-178.

21. Highmore, R. J.; Evetts, J. E.; Greer, A. L.; Somekh, R. E. Appl Phys Lett 1987, 50, 566-568.

22. Highmore, R. J.; Somekh, R. E.; Evetts, J. E.; Greer, A. L. J Less-Common Met 1988, 140, 353-360. 
23. Kissinger, H. E. Anal Chem 1957, 29, 1702-1706.

24. Takeuchi, A.; Inoue, A. Mater Trans 2005, 46, 2817-2829.

25. Schwarz, R. B.; Johnson, W. L. Phys Rev Lett 1983, 51, 415-418.

26. Johnson, W. L. Prog Mater Sci 1986, 30, 81-134.

27. Desre, P. J.; Yavari, A. R. Phys Rev Lett 1990, 64, 1533-1536.

28. Desre, P. J. Acta Metall Mater 1991, 39, 2309-2315.

29. Hodaj, F.; Desre, P. J. Acta Mater 1996, 44, 4485-4490.

30. Greer, A. L. Science 1995, 267, 1947-1953.

31. Schroers, J. Phys Today 2013, 66, 32-37.

32. Greer, A. L. Nature 1993, 366, 303-304.

33. Willaime, F. J Nucl Mater 2003, 323, 205-212.

34. Samolyuk, G. D.; Barashev, A. V.; Golubov, S. I.; Osetsky, Y. N.; Stoller, R. E. Acta Mater 2014, 78, 173-180.

35. Wu, H. H.; Trinkle, D. R. Phys Rev Lett 2011, 107, 045504.

36. Balluffi, R. W.; Allen, S.; Carter, W. C., Chap. 19., Kinetics of materials. John Wiley \& Sons: 2005.

37. Mayer, J.; Giannuzzi, L. A.; Kamino, T.; Michael, J. Mrs Bulletin 2007, 32, 400-407.

38. Kresse, G.; Furthmuller, J. Phys Rev B 1996, 54, 11169-11186.

39. Kresse, G.; Joubert, D. Phys Rev B 1999, 59, 1758-1775.

40. $\quad$ Perdew, J. P.; Burke, K.; Ernzerhof, M. Phys Rev Lett 1996, 77, 3865-3868. 